\title{
Tail Risk and Extreme Events: Connections between Oil and Clean Energy
}

\author{
Elisa Di Febo *(D), Matteo Foglia $\mathbb{D}$ and Eliana Angelini
}

Department of Economics, "G.d'Annunzio" University of Chieti-Pescara, Viale Pindaro 42, 65127 (Pescara), Italy; matteo.foglia@unich.it (M.F.); eliana.angelini@unich.it (E.A.)

* Correspondence: elisa.difebo@unich.it

check for updates

Citation: Di Febo, Elisa, Matteo Foglia, and Eliana Angelini. 2021. Tail Risk and Extreme Events: Connections between Oil and Clean Energy. Risks 9: 39. https://doi.org/ $10.3390 /$ risks9020039

Academic Editor: Mogens Steffensen Received: 29 December 2020 Accepted: 8 Febraury 2021 Published: 11 Febraury 2021

Publisher's Note: MDPI stays neutral with regard to jurisdictional clai$\mathrm{ms}$ in published maps and institutional affiliations.

Copyright: (C) 2021 by the authors. Licensee MDPI, Basel, Switzerland. This article is an open access article distributed under the terms and conditions of the Creative Commons Attribution (CC BY) license (https:// creativecommons.org/licenses/by/ $4.0 /)$.
Abstract: Do tail events in the oil market trigger extreme responses by the clean-energy financial market (and vice versa)? This paper investigates the relationship between oil price and cleanenergy stock with a novel methodology, namely extreme events study. The aim is to investigate an asymmetry effect between the response to good versus bad days. The results show how the two markets influence each other more negatively, i.e., extreme negative events significantly impact the other market. Furthermore, we document how the impact of the shock transmitted by oil prices to clean-energy stocks is less than the amount of shock transmitted oppositely. These findings have important implications for investor and renewable energy policies.

Keywords: extreme events study; tail risk; renewable energy stock; oil price

\section{Introduction}

Recent concerns about climate change have led to significant attention on energy finance, from researchers, academics, investors and policymakers. The study of oil price dynamics and its impact on various markets has been the focus of attention in the literature. In fact, as highlighted by numerous papers (Ahmad 2017; Bondia et al. 2016; Ferrer et al. 2018; Foglia and Angelini 2020; Henriques and Sadorsky 2008; Kumar et al. 2012; Managi and Okimoto 2013; Nasreen et al. 2020; Pham 2019; Reboredo 2015; Reboredo and Ugolini 2016 2018; Sadorsky 2012; Uddin et al. 2019), the dynamics of oil prices impact the performance of renewable companies. This dependence makes it complicated to replace exhaustible energy resources with sustainable energy resources, i.e., substitution effect (Bondia et al. 2016; Ferrer et al. 2018; Monge and Gil-Alana 2020; Reboredo 2015). Furthermore, it is well known that these markets have been affected by structural breaks (events) that have sharper changed the price. Indeed, in recent years oil price has changed with significant increases and decreases (Ellwanger et al. 2017; Zhu et al. 2015). For instance, Ellwanger et al. (2017) argue that both demand and supply factors have been a role in the significant oil price decline of 2014. The OPEC decision to conserve output levels, the growth of shale oil production and a long-delayed output response from a time of higher oil prices played a crucial role initial contract in oil prices. Zhu et al. (2015) used monthly data of real crude oil price and Chinese real stock market at the industry level, and show that sensitivity varies across different industries and periods based on structural breaks and asymmetric effects of oil price change. This dynamic reflects the main events that occurred in the oil market. For example, the political upheaval in the Middle East and North Africa and the war in Libya in 2012; the drop in oil price from 2014 to 2016; the China-United States trade war; the reintroduction of sanctions on Iran in 2018-2019 and finally the COVID-19 outbreak. About the methodology, the literature presents some papers that consider tail dependence as an extreme value. Huynh (2020) exams co-movement between green bonds and triple-a government bonds. The author uses two copulas for normal dependence and Student's $t$ distribution for the heavy tail. Moreover, drawing inspiration by Behrendt et al. (2019), the paper examines the direction for transferring the 
return of green bonds and government bonds. In Huynh et al. (2020), it is analyzed the role of artificial intelligence, robotics stock and green bonds in portfolio diversification using tail dependence as copulas and the Generalized Forecast Error Variance Decomposition. In Pham and Huynh (2020), however, the linkage between green bonds and investor attention used the Google Search Volume Index of the main keyword "green bond" and some index to measure its performance.

Hence, it is essential to consider the possible existence of extreme events in the time series behaviors. For this purpose, the work aims to analyze how extreme (negative and positive) events on the oil market affect the clean-energy sector. In particular, we want to test if there is the asymmetry between the response of clean energy to good days versus bad ones. In recent years, many studies have examined the interaction between the clean (renewable) energy market and the oil market through linear autoregressive models, such as Vector Autoregressive (VAR) (Ahmad 2017; Bondia et al. 2016; Ferrer et al. 2018; Foglia and Angelini 2020; Henriques and Sadorsky 2008; Kumar et al. 2012; Managi and Okimoto 2013). For example, Kumar et al. (2012) study the relationship between clean-energy stock price, the stock price of high technology firms, oil price and carbon price. The authors find that the variation in all indices of clean-energy stocks (expressed as NEX, ECO and SPGCE) is defined by past movements in oil price, in stock price of technology companies and interest rate. Moreover, they underline that there is a positive relationship between oil price and alternative energy sources; in fact, an increase of oil price produces the substitution of alternate energy sources. Also, Managi and Okimoto (2013) find a positive relationship between oil prices and clean-energy prices after a structural break, suggesting a movement from conventional energy to clean-energy. In contrast with Managi and Okimoto (2013), Bondia et al. (2016) demonstrate the presence of cointegration among the four variables with two endogenous structural breaks. The four variables are the stock price of alternative energy companies "WilderHill New Energy Global Innovation Index", the stock prices of technology companies "New York Stock Exchange Arca Tech 100 Index", oil price as the average of weekly closing spot prices of West Texas Intermediate and Brent crude oil, and interest rate as 10-Year Treasury Constant Maturity Rate. This affirmation explains that the existence of structural breaks in the period of the analysis can produce misleading results if they are not incorporated in the cointegration testing model. Ferrer et al. (2018) affirm that the crude oil and financial markets have become more efficient, so, the shock transmission effects occur primarily within one week. The equity market performance of renewable energy companies is likely to be more related to factors such as technology innovation, capital spending, legislation or geographic availability than to oil price. More recently, Foglia and Angelini (2020) investigate the volatility connectedness between oil price and clean-energy firms, including the COVID-19 outbreak. Their results show the strong effect of the pandemic on these financial markets with an increase for the volatility spillovers, also supported by the effects of financial contagion.

However, the above literature estimates the overall average relationship between the variables of interest, without considering the different behaviors in the tail returns. Therefore, the "average" estimation could give misleading answers and findings. To this end, we use the event study methodology proposed by Patnaik et al. (2013). Through this framework, we can take into account extreme events that occur in one market and how these are reflected on the other. One of the advantages of this approach is that it avoids the need to make parametric hypotheses on events, therefore on the behavior of the tails (like Reboredo 2015; Reboredo and Ugolini 2018; Uddin et al. 2019). We identify events that consist of extreme movements in the oil market. On these events (dates), the event study is conducted. This allows us to measure the response of the other market. To our knowledge, is the first paper that investigates the spillover effect of an extreme events (such as COVID-19 outbreak). More specifically, we show the reaction of the clean-energy market to events relevant to the oil market (and vice versa). 


\section{Methodology and Data}

We use daily stock market returns $(\times 100)$ for four clean energy ${ }^{1}$ stock indices and the West Text Intermediate (WTI) oil. In particular, for the clean-energy market we use: (i) NASDAQ OMX Wind Index (Wind), (ii) NASDAQ OMX Solar Index (Solar), (iii) NASDAQ OMX Energy Efficiency Index (Tech) and iv) NASDAQ OMX Renewable Energy Generation (Renewable). Our data covers the period from 1 December 2010 to 28 May 2020 (2441 obs.). Table 1 reports the summary statistics for all the stock returns, while Figure 1 shows the dynamics of daily returns. The clean-energy sector shows the highest means, while the WTI oil has the highest value standard deviations. As we can note, the COVID-19 outbreak is clear, and it is more pronounced for the oil market (Cerboni Baiardi et al. 2020). In fact, the WTI oil "fell \$20 a barrel, dropping to lowest level for 18 years" (Dutta et al. 2020). There is no evidence of unit root (the series are stationary), such as the Augmented Dickey-Fuller test (ADF) test suggests. The Jarque-Bera (JB) statistic for each variable is significant at the $1 \%$ level, then we can reject the null-hypothesis of a Gaussian distribution, as well as the Kurtosis test suggests.
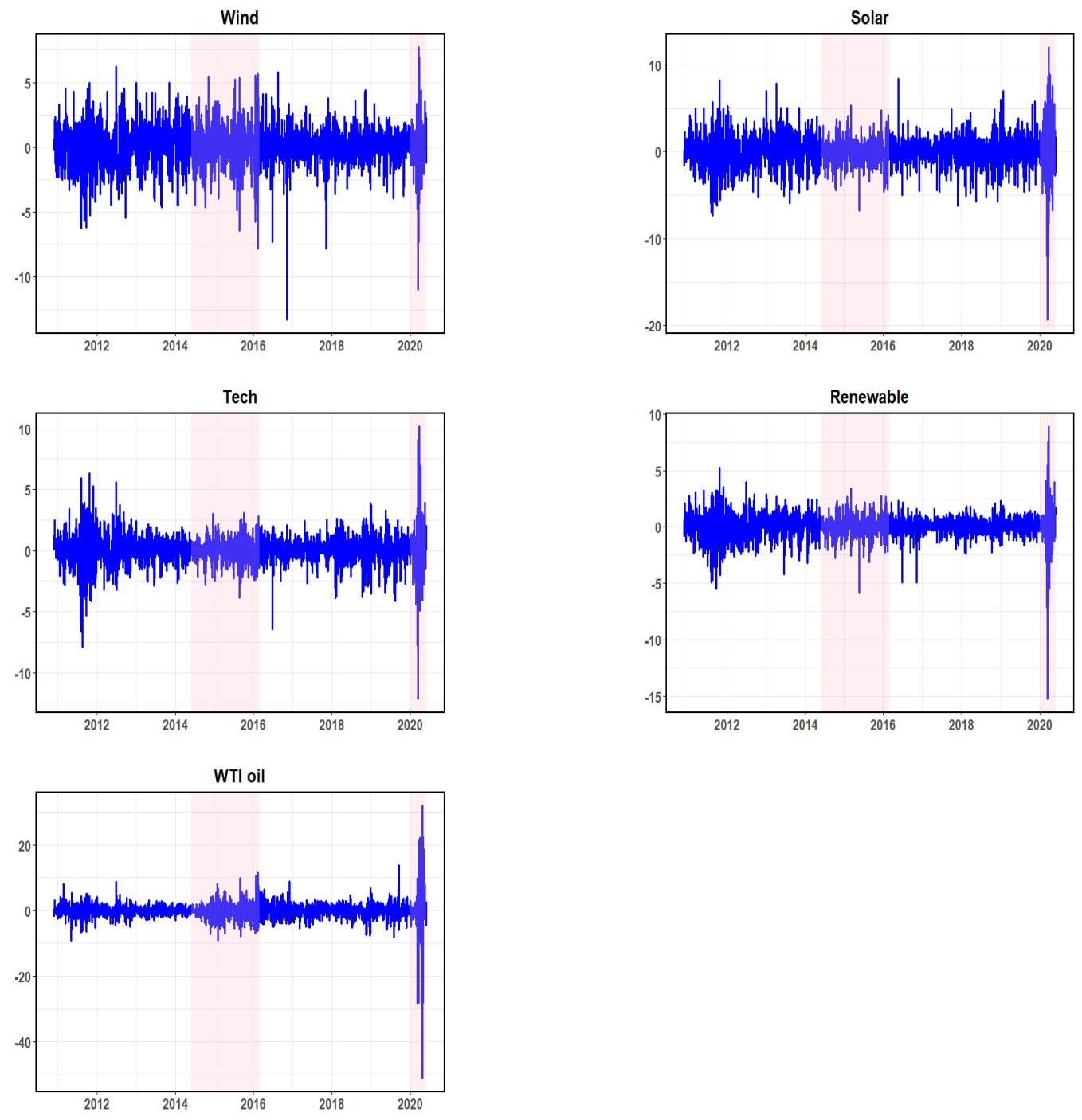

Figure 1. Time series plot of daily returns. The shaded area denotes the period of oil price drop (June 2014 to February 2016) and COVID-19 (January 2020 to 28 May).

1 The North Carolina Sustainable Energy Association defines clean energy as energy derived from renewable, zero-emissions sources, as well as energy saved through energy efficiency measures. 
Table 1. Summary Statistics. The augmented Dickey-Fuller (ADF) statistic tests the null hypothesis of unit root. Each ADF statistic is negative and less than the test critical value at the $1 \%$ significant level, i.e., rejecting the null hypothesis of a unit root in each return series. All Jarque-Bera statistics are significant at the $1 \%$ level, which reject the null hypothesis of Gaussian distribution of return. ${ }^{* * *}$ indicates statistical significance at $1 \%$.

\begin{tabular}{|c|c|c|c|c|c|c|c|c|c|}
\hline & Min & Max & Mean & Median & Stdev & Skewness & Kurtosis & ADF & JB \\
\hline Wind & -13.28 & 7.72 & 0.04 & 0.06 & 1.58 & -0.51 & 5.03 & $-12.61^{* * *}$ & $2688.6^{* * *}$ \\
\hline Solar & -19.33 & 12.05 & 0.02 & 0.05 & 1.94 & -0.65 & 8.50 & $-11.82^{* * *}$ & $7544.5^{* * *}$ \\
\hline Tech & -12.15 & 10.18 & 0.02 & 0.06 & 1.28 & -0.43 & 9.98 & $-13.05^{* * *}$ & $10,241^{* * *}$ \\
\hline Renewable & -15.26 & 8.93 & 0.03 & 0.08 & 1.12 & -1.30 & 20.31 & $-12.22 * * *$ & $42,753^{* * *}$ \\
\hline WTI Oil & -51.00 & 31.96 & -0.04 & 0.06 & 2.91 & -1.95 & 61.01 & $-13.32 * * *$ & $380,884^{* * *}$ \\
\hline
\end{tabular}

\subsection{Methodology}

In this paper, we follow Patnaik et al. (2013) framework, and we define the events "as those dates on which extreme values of returns are observed". Compared to the classic event study methodology, this approach allows us to capture and identify the event in the tail risk, i.e., we can examine the distribution of daily oil returns by identifying the dates when the returns are in the lower (0.05) and upper (0.05) tails. Hence, we define the good event when the stock returns are in the upper (0.95) tail, while bad event when the returns are in lower (0.05) tails of the distribution. This methodology has several advantages. First, is that it does not require distributional assumptions such as normality. Therefore, we do not have to make any assumptions about the distribution. Moreover, it allows us to compute a flexible tail impulse response (Patnaik et al. 2013), an impulse response function computed in the tails, avoiding the assumption of linearity and mean-to-mean dependence as in VAR models (Ferrer et al. 2018; Foglia and Angelini 2020; Henriques and Sadorsky 2008; Kumar et al. 2012). Second, it is a robust approach against serial correlation in the series, which is very relevant for analyzing stock returns. Third, it allows merging all consecutive extreme events, of the same direction, into a single event. This strategy allows us to capture the most important financial crises (events) that happened in different years (sub-prime, sovereign debt crisis, oil decline, COVID-19 pandemic). The use of the extreme event study approach is justified to present fresh evidence of the clean-oil nexus of tail risk, in contrast by previous studies that are based on a mean-to-mean analysis and to check if extreme tail events between the two markets are symmetrically dependent. The latter is particularly relevant in the context of financial risks such as the current one. Therefore, we believe that this method is appropriate for studying turbulence (tail risk) between these two financial markets.

In Table 2, we show the year distribution of extreme events for each variable. Figure 2 displays the daily dynamics of extreme events.

Table 2. Extreme events.

\begin{tabular}{ccccccccccc}
\hline & WTI Oil & & Wind & & Solar & \multicolumn{2}{c}{ Tech } & \multicolumn{3}{c}{ Renewable } \\
\hline Years & Good & Bad & Good & Bad & Good & Bad & Good & Bad & Good & Bad \\
\hline 2011 & 7 & 11 & 10 & 16 & 15 & 10 & 16 & 17 & 18 & 20 \\
2012 & 5 & 3 & 12 & 12 & 7 & 8 & 16 & 9 & 10 & 17 \\
2013 & 0 & 0 & 10 & 10 & 14 & 11 & 4 & 6 & 9 & 10 \\
2014 & 2 & 5 & 15 & 11 & 10 & 8 & 4 & 5 & 13 & 12 \\
2015 & 12 & 14 & 13 & 9 & 5 & 3 & 6 & 7 & 10 & 6 \\
2016 & 13 & 11 & 12 & 7 & 6 & 5 & 10 & 5 & 6 & 8 \\
2017 & 1 & 8 & 7 & 5 & 1 & 6 & 2 & 2 & 1 & 1 \\
2018 & 5 & 10 & 2 & 4 & 8 & 10 & 12 & 8 & 4 & 3 \\
2019 & 12 & 6 & 1 & 5 & 9 & 10 & 10 & 8 & 3 & 0 \\
2020 & 3 & 3 & 5 & 3 & 8 & 4 & 9 & 5 & 7 & 1 \\
\hline TOT & 60 & 71 & 87 & 82 & 83 & 75 & 89 & 72 & 81 & 78 \\
\hline
\end{tabular}



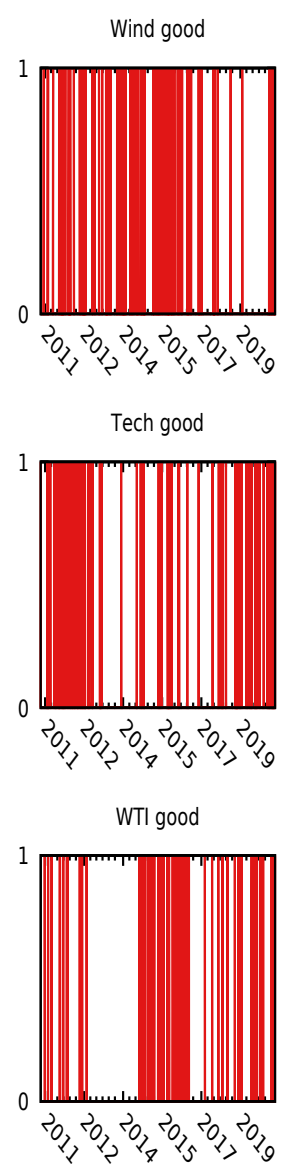

Wind bad

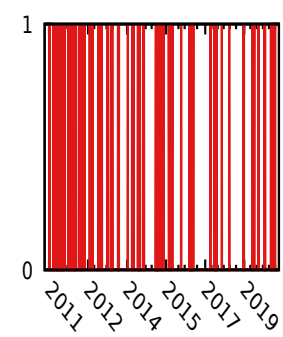

Tech bad

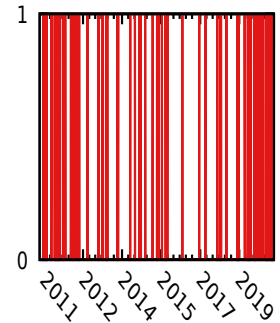

WTI bad

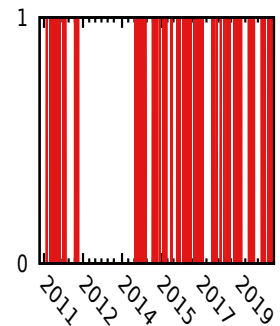

Solar good

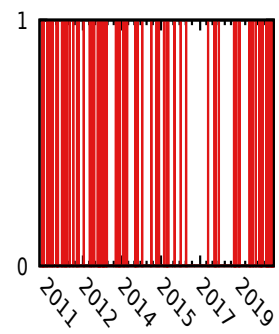

Rene good
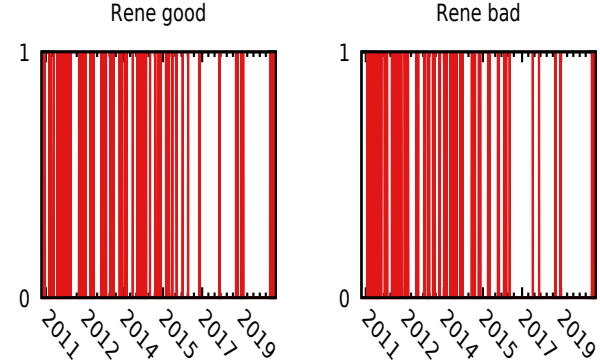

Figure 2. Daily dynamics of good and bad events. 1 indicates the day of an extreme event.

As we can see, from 2011 to 2014, there were many extreme events in the cleanenergy industry. In fact, these years were turbulent for the clean-energy market due to the economic downturn (REN21 2014). Many countries have significantly reduced financial support for this sector, leading to bankruptcies, and this has caused international risk spillover effects (high tail risk). Focusing on WTI oil, as we can expect, many extreme values occur during the drop-oil (2015-2016). During 2020, there are 3 (good and bad) events. For example, we can note Iran's rocket attach (8 January 2020) or the COVID-19 outbreak (27 April 2020) impact.

\subsection{Extreme Event Approach}

Let $r_{t}$ the returns of WTI oil, the upper tail of events is given by:

$$
E^{+}=\{i\} \text { s.t. } r_{t}>Q(r, q)
$$

where $q$ is the quantile and $Q(r, q)$ is identified such that $\operatorname{Pr}\left(r_{t}>Q(r, q)\right)=q$. $E^{-}$stands for the left tail extreme events, hence $E=E^{+} \cup E^{-}$is all extreme events. We define the set of uncontaminated extreme events in the upper tail $E^{+}$ad dates $j$ as followings:

$$
\begin{gathered}
j \in E^{+} \\
(j+k) \notin E \forall k \in\{-W, \ldots,-1,1, \ldots, W\}
\end{gathered}
$$

where $W$ are the days before and after the event. In the case of contaminated events, the returns are merged (cluster) into a single value $\sum_{i=n}^{n+r} r_{i}$ which is used as the event date. Following Patnaik et al. (2013), to estimate the abnormal returns, we use the bootstrap inference strategy based on 1000 replications. The procedure consists of several steps. First, each event is expressed as a time series of cumulative returns $(C R)$, given by the average of 
all $C R$ time series. Second, sampling with event-level replacement is performed. For each event, the corresponding $C R$ time series is taken. Third, this procedure is repeated 1000 times to obtain the complete $C R$ distribution. Finally, the responses are plotting with a 95\% bootstrap confidence interval to verify the significance of events. ${ }^{2}$

We chose 4 days as the length of the interest period around each event. This window seems like a long enough time period to capture anticipatory data or dynamics movements for extreme events (Patnaik et al. 2013). ${ }^{3}$

\section{Empirical Findings}

\subsection{Response of Clean Energy to WTI Oil Extreme Events}

Figures 3-6 show the response of clean-energy market to extreme (good and bad) events on WTI oil market. The confidence interval (dot-line) is built beginning for the first day of the 9-day window (the event and four days prior and after). Focusing on the good extreme event (left side), we can observe how good days on WTI oil have no significant impact on clean energy. We can see that before the days with high positive WTI oil returns, there is unusual activity in the clean market. In fact, the day before the event, we notice an increase in CAR. The market seems to anticipate the event. In the days following the date of the event, the positive effect continues. However, the results are not very significant, i.e., the confidence interval through the zero line. Focusing on the "bad" dates for WTI oil (right-side), we notice that there is evidence of investors selling before the event date. Even for negative days, the market anticipates the fall in oil prices. Figure 3 shows the response of Wind (NASDAQ OMX Wind Index) to extreme events as measured by WTI oil. In the two days preceding the extreme event, it is evident how the negative trend is triggered. This behavior is also highlighted in the Figure 4 (NASDAQ OMX Solar Index), Figure 5 (NASDAQ OMX Energy Efficiency Index) and Figure 6 (NASDAQ OMX Renewable Energy Generation) respectively, in the same two days before the extreme event. It can be said that there is a negative trend in all sectors: Wind, Solar, Tech and Renewable energy. After the date of the event, there is still evidence of negative trading feedback.

Oil sector issues negatively affect the clean sector. As we can see from the confidence interval, the results are all significant in this case. This suggests that the negative returns in the energy sector are the result of price pressure caused by events in the oil market. According to Patnaik et al. (2013), the efficient market response is a step-by-step response on the date of the event and a flat pattern afterwards. The dynamics are relatively flat, i.e., they do not seem to trigger further negative returns. This suggests the efficiency of the markets. Rejections of the null efficiency could be of under-reaction as a slow response towards the long-run outcome; or over-reaction as an extreme response around the event day that is reserved in the following date.

These results show that there is no simple relationship between WTI oil returns and the clean market one. Although the relationship in this case is not strictly causal, the asymmetries between patterns between negative and positive cases suggest that the two markets do not influence each other in both directions. ${ }^{4}$ In other words, the results show that negative events in WTI oil negatively affect the clean sector, but we find no empirical evidence to the contrary. Therefore, the perception of the substitution effect, or that the two markets "crash and boom together" (Reboredo 2015; Uddin et al. 2019), is not empirically supported. This suggests how policymakers when formulating their policies, should consider asymmetric effects to design policies to facilitate the transition to a sustainable energy system (Reboredo 2015). Moreover, our findings show the need to adopt robust policies to stabilize the energy market during the period of large oil price fluctuations.

2 Please see Patnaik et al. (2013) and Shah and Jain (2017) for a mathematically derivation of the model.

3 To test the robustness, we also estimate the model based on an alternative window $(-10 ;+10)$. The results are qualitatively the same, and they are available upon request.

4 To test the COVID-19 outbreak impact, we split the sample in pre- and post-pandemic. The results are the same, and they are available upon request. 

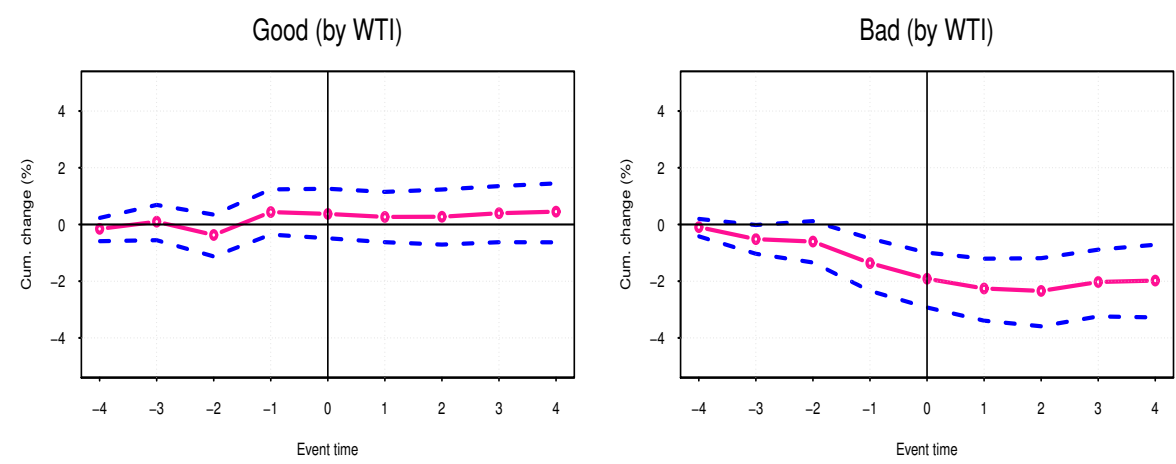

Figure 3. Extreme event on WTI oil and response of Wind.
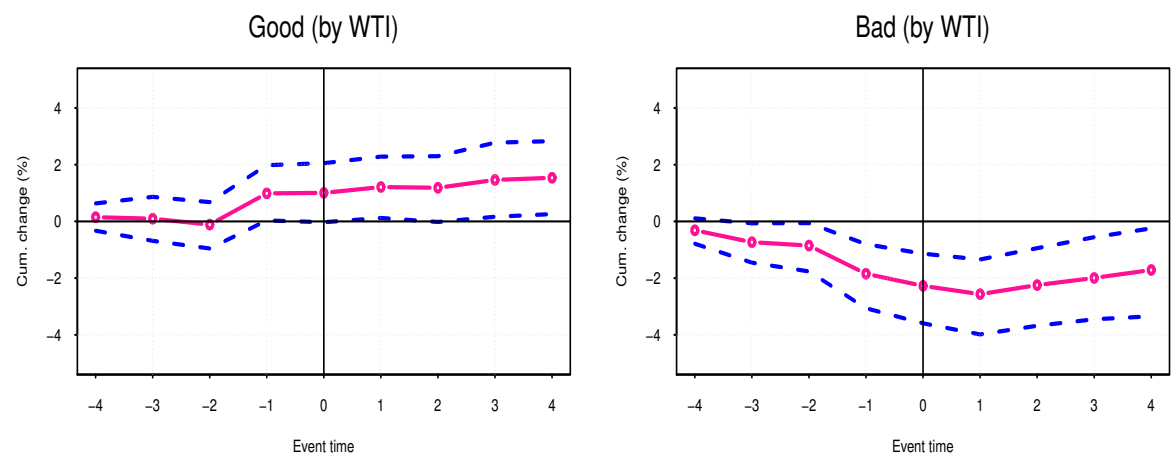

Figure 4. Extreme event on WTI oil and response of Solar.
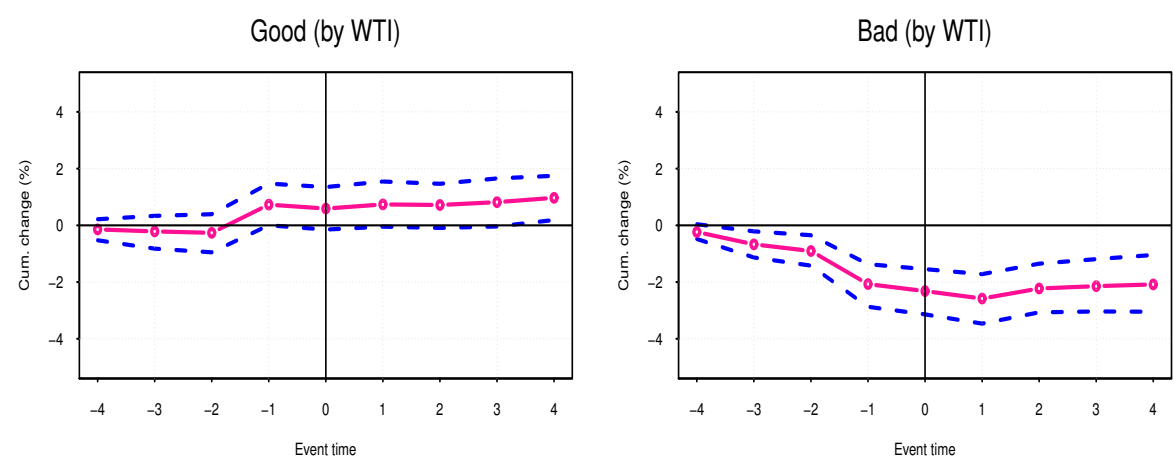

Figure 5. Extreme event on WTI oil and response of Tech.
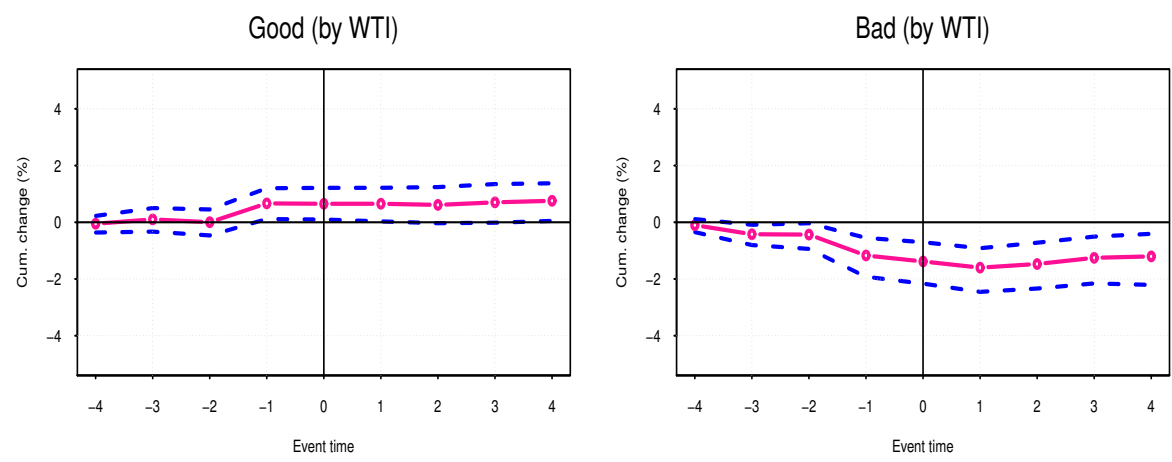

Figure 6. Extreme event on WTI oil and response of Renewable.

\subsection{Response of WTI Oil to Clean Extreme Events}

To better investigate the oil-clean nexus, we analyze the WTI oil response to clean market extreme events. It is evident how, in this case, the results are in line and concord 
with the precedents. The following Figures 7-10 report the "good" events on the left side, while there are the "bad" events to the right. In general, it is evident that the "good" events are not significant.

Figure 7 shows how an extreme event on Wind and the response of WTI oil. Only the "bad" event results significant. Differently from Figure 3 (left side) in which an adverse event in the WTI oil market seems to be predicted two days earlier by the Wind sector with a progressive negative trend; an extreme event in the Wind seems to have been felt two days more before by WTI oil, but already partially absorbed the following day $(t-1)$ with a slight upward trend.
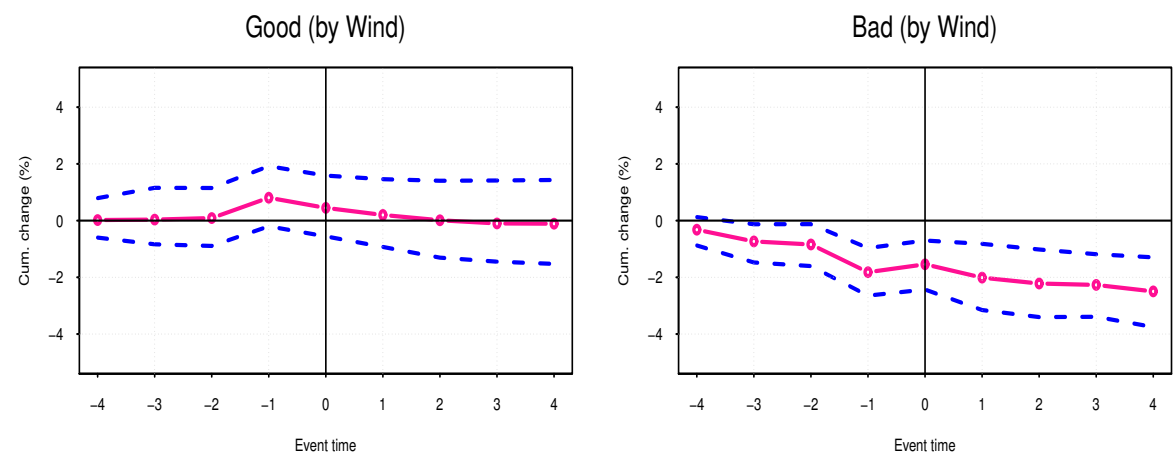

Figure 7. Extreme event on Wind and response of WTI oil.
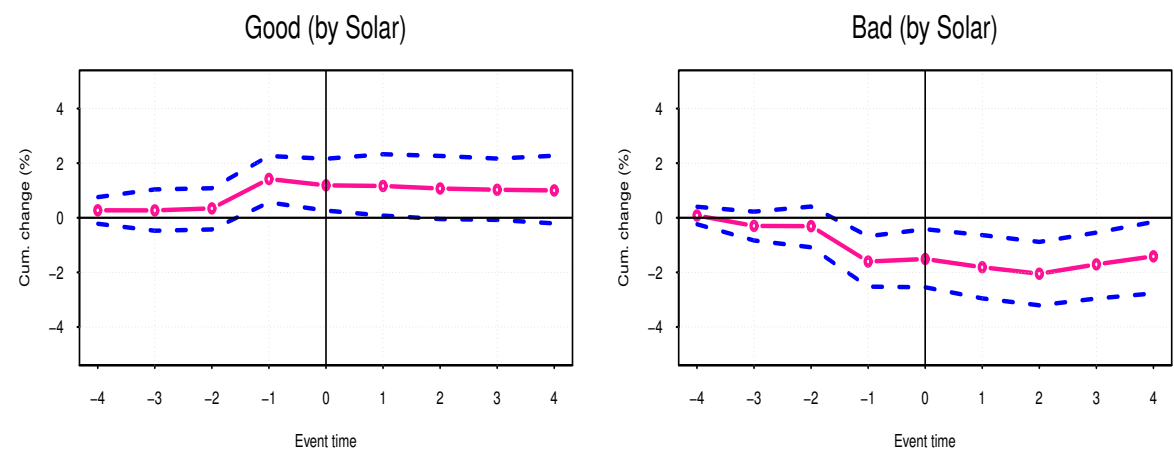

Figure 8. Extreme event on Solar and response of WTI oil.

Figure 8 shows the response of WTI oil at the extreme event on Solar. It is the only one that shows statistical significance in the time between the day before the good event and the day of the event itself. This result is perfectly coherent with the analysis of Reboredo (2015), Kazemilari et al. (2017) and Kim et al. (2019). Indeed, the solar energy sector displays a distinctive systemic risk pattern. The contribution of oil prices to systemic risk is different in magnitude and asymmetric, with a little impact in "good" compared to "bad" extreme oil price movements. Figure 9 refers to an extreme event on the Tech and response of WTI oil, while Figure 10 refers to an extreme event on the Renewable sector and WTI oil response. In both cases, the positive events are not statistically significant, while an extreme adverse event (in both Tech and Renewable) generates a significant oil price movement response. Moreover, it seems that the market can predict the event a day in advance $(t-1)$. 

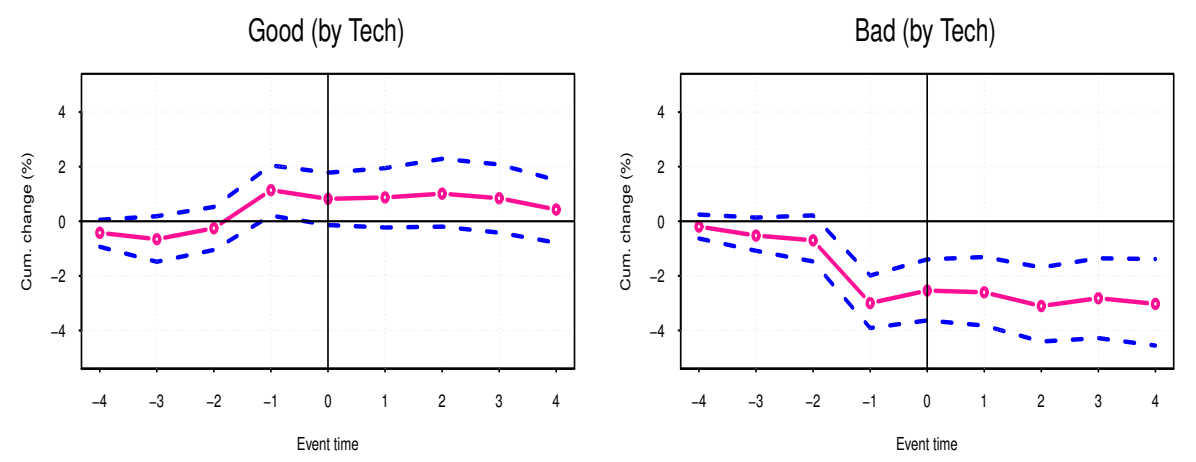

Figure 9. Extreme event on Tech and response of WTI oil.
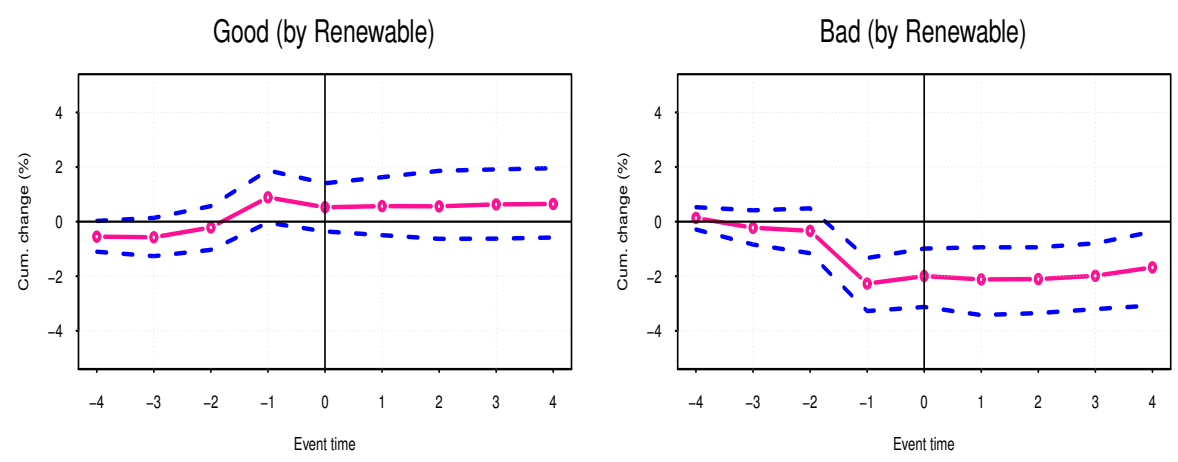

Figure 10. Extreme event on Renewable and response of WTI oil.

Overall, the main results can be summarized as follows. The two markets influence each other more negatively, i.e., extreme negative events have a significant impact on the other market (downside tail risk spillover effects). The impact of the shock transmitted by oil prices to clean-energy stocks is less than the amount of shock transmitted in the opposite way. These results are perfectly in line with Lundgren et al. (2018); Ferrer et al. (2018); Pham (2019); Uddin et al. (2019) and Foglia and Angelini (2020), who document this asymmetric effect.

\subsection{Robustness Check}

In this section, to check the robustness of the previous results, we compute the analysis using Brent oil as in Tiwari et al. (2020). In particular, we test the extreme event of Brent oil on general Renewable index. Figures 11 and 12 show the results of event studies. As we can see, the dynamics are qualitatively similar to Figures 6 and 10, suggesting that the clean-energy response dynamic of extreme event of oil market (and vice versa) is robust to the choice of alternative oil prices.

Moreover, to show the robustness of the results, we compute the cross-quantilogram framework proposed by Han et al. (2016). ${ }^{5}$ This econometric model helps estimate the lead-lag relation and capture the directional quantile dependence between two times series at different lags and quantiles. We can highlight the clean-oil nexus (tail) relationships; hence we are able to check if extremely high and low risks across WTI oil (clean) are symmetrically dependent, and vice versa. Figure 13 plots the cross-quantilogram $(\hat{p}(k))$. We calculate the $95 \%$ bootstrap confidence intervals (blue line) based on 1000 replication and the cross-correlogram (pink line), for low (0.05) and high (0.95) quantiles. The findings show how these markets negatively influence each other, i.e., the cross-quantilogram is significant for several delays ( $\hat{p}(k)$ crosses the confidence interval). On the other hand,

5 Please see Han et al. (2016) for the econometric derivation of the model. 
$\hat{p}(k)$ is not significant in the upper (0.95). This result is perfectly in line with the previous findings, which confirms the robustness of the main results.
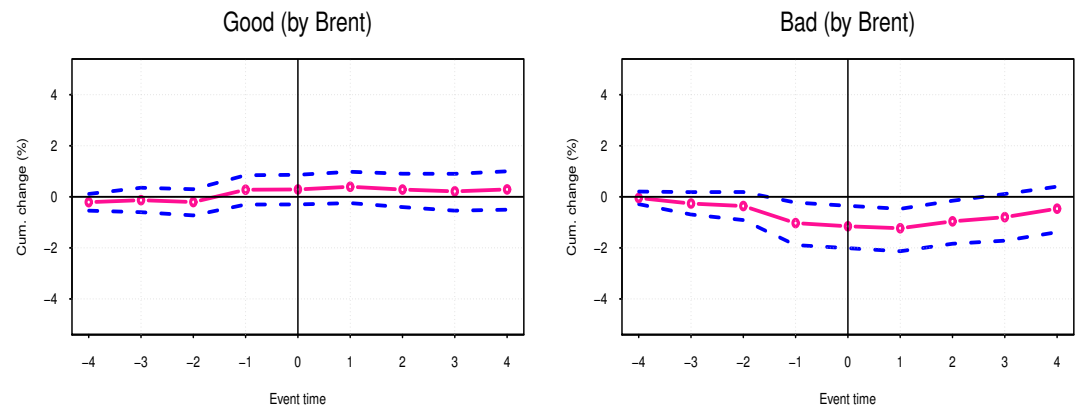

Figure 11. Extreme event on Brent oil and Renewable response.
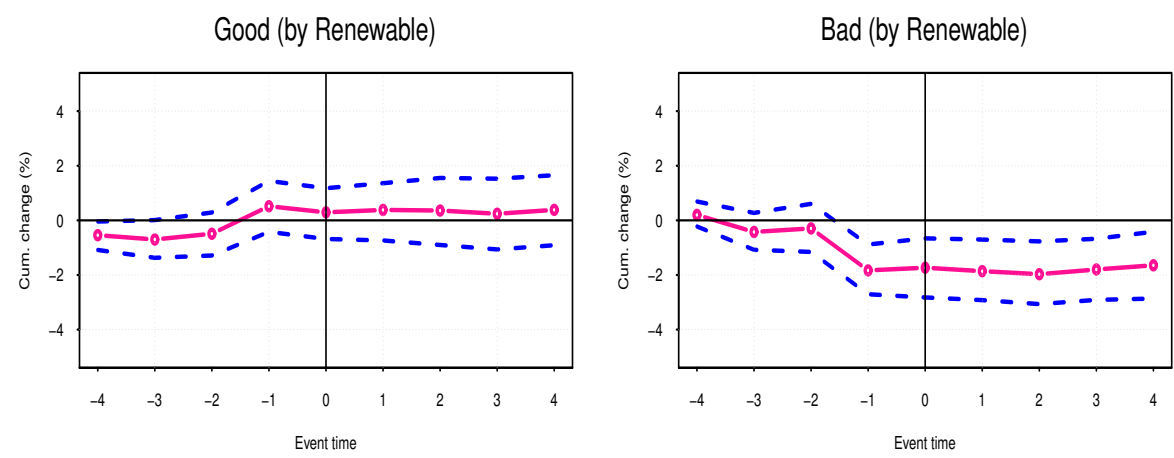

Figure 12. Extreme event on Renewable and response of Brent oil.
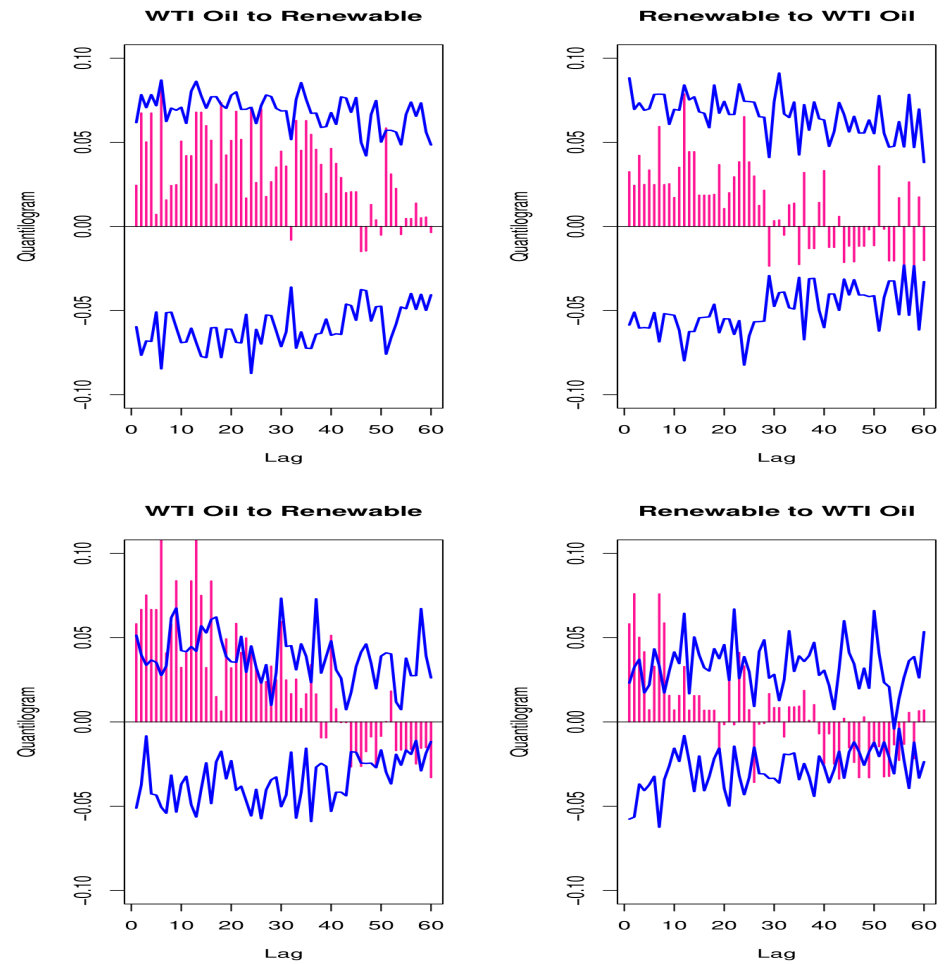

Figure 13. Cross-quantilogram. In the upper the Cross-quantilogram plot for $\theta=0.95$ (good), while in the lower for $\theta=0.05$ (bad). 


\section{Conclusions and Policy Implications}

In recent years, the attention to climate change and costly fossil fuel has stimulated the development of the renewable energy sector. Many investors and investment funds have focused on renewable energies such as wind, solar power and biofuels; therefore, investing money in these environmentally friendly companies. The performance of renewable firms depends more on the behavior of oil prices, which partially determine the economic viability of substitution between exhaustible and sustainable energy resources. Therefore, to know how extreme event on the WTI oil price impacts the performance of renewable energy index is crucial information for investors with renewable assets in their portfolios. Significantly, the investors need to evaluate the changes' in risk up or down that result from oil changes. It is crucial because the information on the dynamic dependence relationship and causality between oil and renewable energy index prices have implications for risk management decisions.

The paper aims to test the response of clean-energy market to extreme (good or bad) events on WTI oil market. One of the advantages of this approach is that it avoids the need to make parametric hypotheses on an event, therefore on the behavior of the tail risks. The methodology allows identifying the "events" as extreme movements in the oil market (or clean energy). The event study is conducted on this "event" (dates), and thus permit us to measure the response of the other market. It is emphasized that this paper, at least according to our knowledge, is the first paper that investigates the spillover effect of extreme events such as COVID-19 outbreak. More specifically, the results show as the good extreme events on the WTI oil have no significant impact on clean energy. It only highlights that one day before the day with a high positive WTI oil returns, there is unusual activity in the renewable energy market. On the contrary, the negative dates for WTI oil show the investors selling before the event; it can be said that the market anticipates the fall in oil prices. The adverse trading movements also continue after the extreme event. It is proven that oil sector issues negatively affect the clean sector. These affirmations are valid for all renewable energy analyzed: Solar, Wind and Tech.

Another important aspect is the implications for policymakers. The starting point is to consider if the interactions by oil and clean energy are endogenous for policymakers (they can alter interactions) or exogenous (they cannot change the interactions). In the first case, policymakers could try to favor the desired form of interaction; while in the second case, they could attempt to exploit existing interactions. In general, it is much difficult to determine with certainty whether the interactions are exogenous or endogenous. Still, policymakers must be keenly aware of the existing kind of interaction among cleanenergy sources and between oil and clean-energy sources. As renewable energy markets are increasingly important, needed policy actions should be taken to guarantee price stability in times of economic turbulence such as today. Also, the impact of the epidemic of COVID-19 on the clean-energy sector is difficult to predict. However, policymakers should develop more policies, such as subsidies that can stimulate the development of the sector, always considering the possibility of establishing a predatory-prey relationship between the various clean energies (Dominioni et al. 2019). They need to understand how extreme event on the oil market impact on the renewable energy market to design more effective policy instruments that can be used to foster the renewable energy sector. Also, the governments need to assess the upside and downside risk to quantify subsidization programs. For example, a tax on gas emissions, would reduce the demand for fossil energy and increase the use of climate hedge portfolios. These events increase the price and reduce the expected returns (lower expected return corresponds to the insurance premium paid). An interesting future study could quantify the cost of climate hedge portfolios by looking at the associated risk premia. For example, to the extent that renewable energy firms reduce their capital cost. This might allow clean firms to achieve efficient scale faster, thereby affecting gas emissions. The design of structural asset pricing models that feature such general equilibrium feedback loops seems a promising direction for research. The same goes for hedging costs with news that can represent an extreme event. Moreover, 
it is concluded that expanding renewable energy can, in principle, reduce an economy's vulnerability to oil price volatility, but a country-specific analysis would be necessary to identify concrete policy measures. A limitation of this paper concerns the response of tail risk. As already explained previously, the dynamics of WTI oil or the clean-energy markets may be influenced by other endogenous and exogenous effects. Therefore, a possible future methodological development could be to combine the extreme event study with the network analysis approach proposed by Antonakakis et al. (2020). This new method would capture how extreme events in one market affect others and vice versa, from a network perspective. In conclusion, the analysis supplies the tool to facilitate the optimal allocation of resources in renewable energies.

Author Contributions: The current paper is a combined effort of E.D.F., M.F. and E.A. Conceptualisation, M.F. and E.D.F.; data curation, M.F.; formal analysis, M.F. and E.D.F.; methodology, M.F.; software, M.F.; writing-original draft preparation, E.D.F. and M.F.; writing-review and editing, E.D.F. and E.A.; supervision, E.A. All authors have read and agreed to the published version of the manuscript.

Funding: This research received no external funding.

Institutional Review Board Statement: Not applicable.

Informed Consent Statement: Not applicable.

Data Availability Statement: The data presented in this study are available on request from the corresponding author.

Conflicts of Interest: The authors declare no conflict of interest.

\section{References}

Ahmad, Wasim. 2017. On the dynamic dependence and investment performance of crude oil and clean energy stocks. Research in International Business and Finance 42: 376-89. [CrossRef]

Antonakakis, Nikolaos, Ioannis Chatziantoniou, and David Gabauer. 2020. Refined measures of dynamic connectedness based on time-varying parameter vector autoregressions. Journal of Risk and Financial Management 13: 84. [CrossRef]

Behrendt, Simon, Thomas Dimpfl, Franziska J. Peter, and David J. Zimmermann. 2019. Rtransferentropy-Quantifying information flow between different time series using effective transfer entropy. SoftwareX 10: 100265. [CrossRef]

Bondia, Ripsy, Sajal Ghosh, and Kakali Kanjilal. 2016. International crude oil prices and the stock prices of clean energy and technology companies: Evidence from non-linear cointegration tests with unknown structural breaks. Energy 101: 558-65. [CrossRef]

Cerboni Baiardi, Lorenzo, Massimo Costabile, Domenico De Giovanni, Fabio Lamantia, Arturo Leccadito, Ivar Massabó, Massimiliano Menzietti, Marco Pirra, Emilio Russo, and Alessandro Staino. 2020. The dynamics of the s\&p 500 under a crisis context: Insights from a three-regime switching model. Risks 8: 71.

Dominioni, Goran, Alessandro Romano, and Chiara Sotis. 2019. A quantitative study of the interactions between oil price and renewable energy sources stock prices. Energies 12: 1693. [CrossRef]

Dutta, Anupam, Elie Bouri, Gazi Salah Uddin, and Muhammad Yahya. 2020. Impact of covid-19 on global energy markets. IAEE Energy Forum Covid-19 Issue 2020: 26-29.

Ellwanger, Reinhard, Benjamin Sawatzky, Konrad Zmitrowicz. 2017. Factors behind the 2014 oil price decline. Bank of Canada Review 2017: 1-13.

Ferrer, Román, Syed Jawad Hussain Shahzad, Raquel López, and Francisco Jareño. 2018. Time and frequency dynamics of connectedness between renewable energy stocks and crude oil prices. Energy Economics 76: 1-20. [CrossRef]

Foglia, Matteo, and Eliana Angelini. 2020. Volatility connectedness between clean energy firms and crude oil in the covid-19 era. Sustainability 12: 9863. [CrossRef]

Han, Heejoon, Oliver Linton, Tatsushi Oka, and Yoon-Jae Whang. 2016. The cross-quantilogram: Measuring quantile dependence and testing directional predictability between time series. Journal of Econometrics 193: 251-70. [CrossRef]

Henriques, Irene, and Perry Sadorsky. 2008. Oil prices and the stock prices of alternative energy companies. Energy Economics 30: 998-1010. [CrossRef]

Huynh, Toan Luu Duc. 2020. When 'green'challenges 'prime': Empirical evidence from government bond markets. Journal of Sustainable Finance \& Investment 1-14. [CrossRef]

Huynh, Toan Luu Duc, Erik Hille, and Muhammad Ali Nasir. 2020. Diversification in the age of the 4th industrial revolution: The role of artificial intelligence, green bonds and cryptocurrencies. Technological Forecasting and Social Change 159: 120188. [CrossRef]

Kazemilari, Mansooreh, Abbas Mardani, Dalia Streimikiene, and Edmundas Kazimieras Zavadskas. 2017. An overview of renewable energy companies in stock exchange: Evidence from minimal spanning tree approach. Renewable Energy 102: 107-17. [CrossRef] 
Kim, BumChoong, Juhan Kim, and Jinsoo Kim. 2019. Evaluation model for investment in solar photovoltaic power generation using fuzzy analytic hierarchy process. Sustainability 11: 2905. [CrossRef]

Kumar, Surender, Shunsuke Managi, and Akimi Matsuda. 2012. Stock prices of clean energy firms, oil and carbon markets: A vector autoregressive analysis. Energy Economics 34: 215-226. [CrossRef]

Lundgren, Amanda Ivarsson, Adriana Milicevic, Gazi Salah Uddin, and Sang Hoon Kang. 2018. Connectedness network and dependence structure mechanism in green investments. Energy Economics 72: 145-153. [CrossRef]

Managi, Shunsuke, and Tatsuyoshi Okimoto. 2013. Does the price of oil interact with clean energy prices in the stock market? Japan and the World Economy 27: 1-9. [CrossRef]

Monge, Manuel, and Luis A. Gil-Alana. 2020. The lithium industry and analysis of the beta term structure of oil companies. Risks 8: 130. [CrossRef]

Nasreen, Samia, Aviral Kumar Tiwari, Juncal Cuñado Eizaguirre, and Mark E. Wohar. 2020. Dynamic connectedness between oil prices and stock returns of clean energy and technology companies. Journal of Cleaner Production 260: 121015. [CrossRef]

Patnaik, Ila, Ajay Shah, and Nirvikar Singh. 2013. Foreign investors under stress: Evidence from india. International Finance 16: 213-44. [CrossRef]

Pham, Linh. 2019. Do all clean energy stocks respond homogeneously to oil price? Energy Economics 81: 355-79. [CrossRef]

Pham, Linh, and Toan Luu Duc Huynh. 2020. How does investor attention influence the green bond market? Finance Research Letters 35: 101533. [CrossRef]

Reboredo, Juan C. 2015. Is there dependence and systemic risk between oil and renewable energy stock prices? Energy Economics 48: 32-45. [CrossRef]

Reboredo, Juan C., and Andrea Ugolini. 2016. Quantile dependence of oil price movements and stock returns. Energy Economics 54: 33-49. [CrossRef]

Reboredo, Juan C., and Andrea Ugolini. 2018. The impact of energy prices on clean energy stock prices. A multivariate quantile dependence approach. Energy Economics 76: 136-52. [CrossRef]

REN21. 2014. Renewables 2016 - Global Status Report. Technical Report, Renewable Energy Policy Network for the 21st Century. Paris: REN21 Secretariat.

Sadorsky, Perry. 2012. Correlations and volatility spillovers between oil prices and the stock prices of clean energy and technology companies. Energy Economics 34: 248-55. [CrossRef]

Shah, Ajay, and Sargam Jain. 2017. Introduction to the Eventstudies Package in R. Available online: https://CRAN.R-project.org/ package=eventstudies (accessed on 10 February 2020)

Tiwari, Aviral Kumar, Samia Nasreen, Subhan Ullah, and Muhammad Shahbaz. 2020. Analysing spillover between returns and volatility series of oil across major stock markets. International Journal of Finance $\mathcal{E}$ Economics. [CrossRef]

Uddin, Gazi Salah, Md Lutfur Rahman, Axel Hedström, and Ali Ahmed. 2019. Cross-quantilogram-based correlation and dependence between renewable energy stock and other asset classes. Energy Economics 80: 743-59. [CrossRef]

Zhu, Huiming, Yawei Guo, and Wanhai You. 2015. An empirical research of crude oil price changes and stock market in china: evidence from the structural breaks and quantile regression. Applied Economics 47: 6055-74. [CrossRef] 